\title{
Ionization Mechanisms Related to Negative Ion APPI, APCI, and DART
}

\author{
Charles N. McEwen ${ }^{\mathrm{a}}$ and Barbara S. Larsen ${ }^{\mathrm{b}}$ \\ ${ }^{a}$ Department of Chemistry and Biochemistry, University of the Sciences in Philadelphia, Philadelphia, \\ Pennsylvania, USA \\ ${ }^{b}$ DuPont Corporate Center for Analytical Sciences, Wilmington, Delaware, USA
}

\begin{abstract}
A recent report found that negative ion atmospheric pressure photoionization (Ni-APPI) and direct analysis in real time (Ni-DART) ionize compounds by electron capture, dissociative electron capture, proton abstraction, and anion adduction. The authors of this report suggested that the common ionization of Ni-APPI and Ni-DART demonstrated that these techniques ionize a wider array of compounds than negative ion atmospheric pressure chemical ionization (Ni-APCI). Here we show that Ni-APCI, using the atmospheric sample analysis probe (ASAP) technique, in the absence of solvent vapors, ionizes the same and similar compounds by the same reported mechanisms. These results are supported by previous publications, which show that each mechanism is active for Ni-APCI. This work demonstrates that irrespective of the initial method of ionization, at atmospheric pressure, similar ion/ electron-molecule chemistries prevail. (J Am Soc Mass Spectrom 2009, 20, 1518-1521) (C) 2009 American Society for Mass Spectrometry
\end{abstract}

$\mathrm{R}$ ecent papers [1,2] published in this journal stated that because negative ion $(\mathrm{Ni})$ atmospheric pressure photoionization (APPI) and direct analysis in real time (DART) can produce negative ions by electron capture (EC), dissociative $\mathrm{EC}$, proton abstraction, and halide attachment, that these methods obviously ionize a wider array of compounds than $\mathrm{Ni}$ atmospheric pressure chemical ionization (APCI), electrospray ionization (ESI), or even chemical ionization (CI). The authors provided no supporting evidence for this statement and attributed the similar results between Ni-DART and Ni-APPI to a unique ionization in $\mathrm{Ni}$-DART. The latter statement was recently referenced [3] as support for a unique ionization mechanism for DART.

Likely, the reference in these papers [1,2] to ESI was meant to be restricted to volatile compounds and the reference to APCI to the common method of use, which is introduction of analyte in solvent. It is a common belief, at least for positive ion mass spectrometry (MS), that photoionization (PI), especially for low polarity compounds, is more inclusive than APCI. This assumption is likely the result of comparisons between liquid introduction APCI and dopant-enhanced liquid introduction APPI [4]. However, the initial reports of atmospheric pressure ionization (API) out of Horning's group using vaporization, gas, and liquid introduction of analyte [5-8]. APCI, [7], and to some extent APPI [9],

Address reprint requests to Dr. C. N. McEwen, Department of Chemistry and Biochemistry, University of the Sciences in Philadelphia, 600 South 43rd St., Philadelphia PA 19104, USA. E-mail: c.mcewen@usp.edu are compromised by solvent vapors that suppress ionization of many low polarity compounds [10].

Because solvent vapors, except where intentionally introduced, were not used with Ni-DART, the comparison with Ni-APCI should also be without solvent vapors in the ionization region. The atmospheric samples analysis probe (ASAP) technique introduces analyte into the API source without solvent, similar to the DART technique, with ionization initiated by a discharge at atmospheric pressure, as reported by Horning et al. [6] Here we demonstrate with experiments and literature references that all of the ionization mechanisms noted above are operative in Ni-APCI. The ASAP [11] method was used to introduce into the Ni-APCI source similar or identical compounds used by Song et al. [1]

\section{Experimental}

The following compounds were obtained from Sigma Aldrich (St. Louis, MO): polyethylene glycol (PEG) 1000 , fullerene $C_{60}$, methylene chloride, and 2,3,6trinitrophenol; 2,6-Di-tert-butyl-4-nitrophenol was a synthetic sample of unknown origin, but $>97 \%$ purity was determined by gas chromatography. PerfluorokeroseneH (PFK) was obtained from PCR Research (Gainesville, FL). All samples were introduced on the closed end of a melting point tube into the Ion Max source of a LTQ-Orbitrap (ThermoFisher Scientific, San Jose, CA) mass spectrometer modified using an ASAP-MS probe ( $\mathrm{M}$ and $\mathrm{M}$ Mass Spec, Wilmington, DE). The sample was vaporized using the heated nitrogen gas stream from the Ion Max source's APCI probe. The tempera- 
ture of the gas was set using the instrument software to $250{ }^{\circ} \mathrm{C}$ for all samples except $\mathrm{C}_{60}$, in which case $450{ }^{\circ} \mathrm{C}$ was used. Methylene chloride was infused into the source region through the APCI probe at $25 \mu \mathrm{L} / \mathrm{min}$ for the analysis of PEG 1000. The ion source was set to run in the negative ion mode using the LTQ Orbitrap set at 30,000 resolution ( $50 \%$ valley definition). The voltage on the discharge needle of the APCI Ion Max configuration was set at $-4000 \mathrm{~V}$. The negative ion tuning parameters were obtained using the standard method provided by the manufacturer and were not updated for these experiments. The instrument was not calibrated for these experiments but the mass accuracy was checked to be accurate within $0.1 \mathrm{Da}$ using compounds of known molecular weight.

\section{Results and Discussion}

In a comparison of Ni-APPI and Ni-DART ionization, the similarity of ions produced by the two methods is ascribed to a unique mechanism of ionization in DART [1]. This statement is based on both methods ionizing compounds by the mechanisms of EC, dissociative EC, proton abstraction, and halide adduction, and led to the conclusion that these techniques ionize a wider array of compounds than Ni-APCI. However, several studies of Ni-APCI have shown this method to have excellent sensitivity, especially for compounds with positive electron affinity (EA) $[5,12,13]$. Early work with APCI was primarily carried out using gas chromatographic introduction and, thus, the ion source was solvent free [13-17]. In particular, GC/APMS operated in the negative ion mode was demonstrated to be a highly sensitive method for detecting a number of environmentally important compounds [14, 18]. Femtogram sensitivity was demonstrated as early as 1990 for 2-aminofluorene using GC/NiAPCI-MS [12].

Here we use the ASAP method to introduce samples into an APCI ion source without the necessity for solvent addition, although solvents can be employed to modify the ionization process [11, 19]. An example using negative ionization in which solvent is beneficial is the introduction of methylene chloride into the ion source for the purpose of producing ions by chloride attachment, one of the four mechanisms discussed in recent papers [1, 2]. Methylene chloride was used to aid ionization of PEG in the negative ion mode by chloride adduction, and was reported as evidence of the anion adduction mechanism for Ni-APPI and Ni-DART [1]. Figure 1 shows the Ni-APCI mass spectrum obtained when methylene chloride vapors are introduced to the ionization region through the APCI probe with sample introduction using the ASAP probe. The major ions observed are $\mathrm{Cl}^{-}$addition to the PEG oligomers. Thus, anion adduction is an ionization mechanism that is observed in Ni-APCI as well as Ni-APPI and Ni-DART.

ASAP-MS without solvent uses nitrogen gas to purge the ion source. Under nitrogen atmosphere conditions, EC is demonstrated in Ni-APCI with excellent

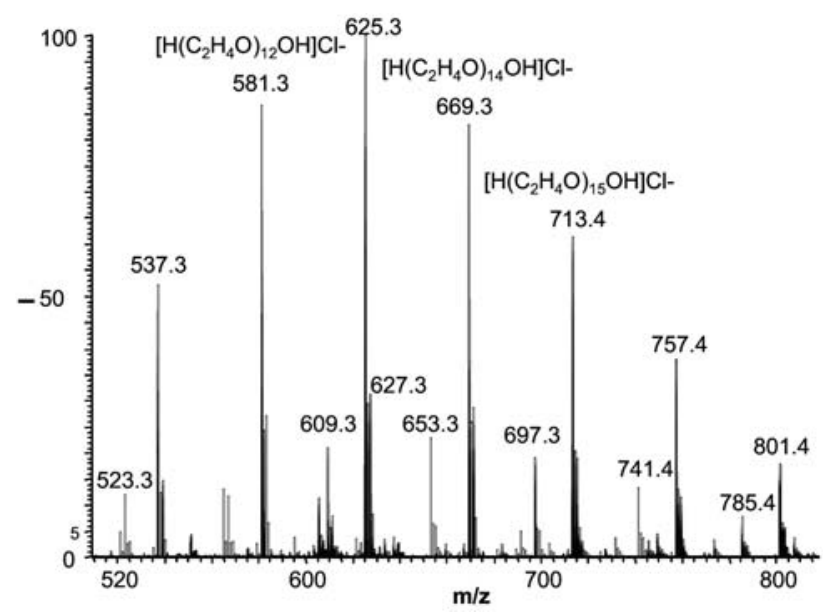

Figure 1. Negative ion APCI mass spectrum of PEG $1000 \mathrm{ob}-$ tained using the ASAP probe method and addition of $25 \mu \mathrm{L} / \mathrm{min}$ of methylene chloride through the APCI probe. Ionization is by $\mathrm{Cl}^{-}$adduction as in Ni-APPI and Ni-DART [1].

sensitivity in the analysis of C60. Figure 2 shows the molecular ion region of the Ni-APCI full acquisition mass spectrum of $20 \mathrm{pg}$ of $\mathrm{C}_{60}$ using the ASAP method and acquired on an LTQ-Orbitrap. Although, at this level of sample, there is significant background chemical noise, the electronic $\mathrm{S} / \mathrm{N}$ ratio as calculated by the instrument software for the molecular ion is $>100$. This acquisition was achieved by using a generic tune for negative ions; therefore, likely the sensitivity can be improved through optimization. Additionally, Figure 2 shows a single acquisition obtained at 30,000 mass resolution $(\mathrm{m} / \Delta \mathrm{m}, 50 \%$ valley) in $0.5 \mathrm{~s}$. Using the method of Song et al. [2] of determining the sensitivity by the amount of sample consumed to generate the spectrum, we arrive at a limit of detection (LOD) of $<1$ pg. Song et al. reported the LOD for C60 with Ni-APPI to be $0.15 \mathrm{pg}$, and for Ni-DART, $400 \mathrm{ng}$ produced a S/N ratio of 100 [1].

The EC mechanism for Ni-APCI is also observed for 2,4,6-trinitrophenol using the ASAP method. For this compound, a full acquisition spectrum with a $S / N>20$ was obtained from $500 \mathrm{fg}$ loaded on a melting point tube. Previous results showing EC and dissociative EC of isomeric tetrachlorodibenzo-p-dioxins were presented by Horning et al. [5] and Mitchum et al. [13] Thus, EC is an active and sensitive mechanism for producing $\mathrm{M}^{-\cdot}$ ions from compounds with positive EA by APCI, but it is not the only mechanism. An alternative means of $\mathrm{M}^{+}$ion formation when oxygen is present is $\mathrm{O}_{2}{ }^{-} \cdot$ addition to the neutral molecule, $\mathrm{M}$, to form the intermediate $\left[\mathrm{MO}_{2}\right]^{-}$. that can dissociate to form $\mathrm{M}^{-}$. plus $\mathrm{O}_{2}$. [20] This reaction is reversible so that with high levels of oxygen, the reaction of $\mathrm{M}^{-}$. formed by $\mathrm{EC}$ with $\mathrm{O}_{2}$ produces the $\left[\mathrm{MO}_{2}\right]^{-}$. Intermediate, which in turn can fragment by other mechanisms (e.g., loss of $\mathrm{OCl}$ from chloronitrobenzene to produce the phenoxide ion) [20]. The latter reactions should be 
expected to be more prominent with open air ion sources.

Singh et al. [21] also previously demonstrated dissociative EC by liquid introduction Ni-APCI. These authors tagged molecules with a pentafluorobenzyl moiety and observed dissociative EC by the loss of the pentafluorobenzyl radical to give an $[\mathrm{M}-\mathrm{PFB}]^{-}$ion. They were able to detect $200 \mathrm{fg}$ of tagged estrone. Song et al. [1] reported EC and dissociative EC using NiDART with PFK; primarily, dissociative EC was observed using Ni-APPI for this mixture of perfluoroalkanes. Figure 3 shows a nearly identical mass spectrum to that published by Song et al. [1] but obtained using the ASAP method instead of Ni-DART, thus indicating that Ni-APCI and Ni-DART are more similar to each other than to Ni-APPI. The mass spectral differences between Ni-DART/Ni-APCI and Ni-APPI suggest that Ni-APPI has a population of more energetic electrons. These results clearly show dissociative EC to be an active mechanism with $\mathrm{Ni}-\mathrm{APCI}$.

Finally, the proton abstraction mechanism is common in Ni-APCI. Shen et al. [22] recently demonstrated, using liquid introduction $\mathrm{Ni}-\mathrm{APCI}$, that $[\mathrm{M}-\mathrm{H}]^{-}$ions are produced for several cyclic peptides with an LOD of ca. 3 ng. Proton abstraction negative ion mass spectra were also obtained with high sensitivity using the ASAP method with 2,6-dibutyl-4-nitrophenol. A mass spectrum was obtained at $20 \mathrm{pg}$ with $[\mathrm{M}-\mathrm{H}]^{-}$being the only ion observed with an abundance above $10 \%$. The $[\mathrm{M}-\mathrm{H}]^{-}$ion from $1 \mathrm{ng}$ of phenol using the ASAP method indicated similar sensitivity to that reported for Ni-DART for phenol [1]. The likely mechanism for [M $\mathrm{H}]^{-}$ion formation is ascribed by Song et al. [1] to proton abstraction by the $\mathrm{HO}_{2}{ }^{-}$ion for Ni-APPI as well as possible dissociative EC. In APCI, the hydrogen ab-

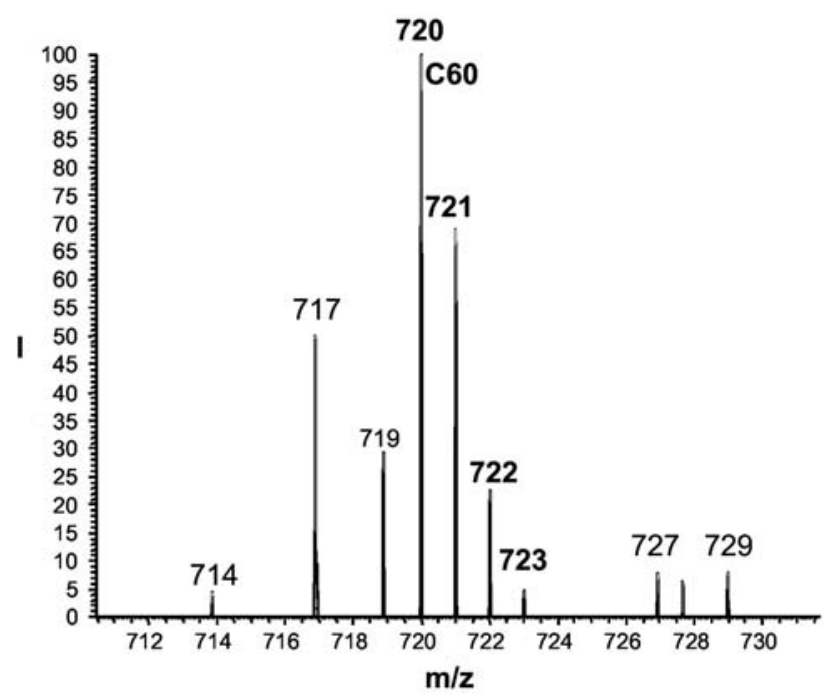

Figure 2. Molecular ion region of a $0.5 \mathrm{~s}$ acquisition obtained using the ASAP method by vaporizing $20 \mathrm{pg}$ of $\mathrm{C}_{60}$ placed on a melting point tube using $450 \mathrm{C}$ nitrogen gas. The predominant ionization is electron capture in agreement with results obtained by Ni-APPI and Ni-DART [1].

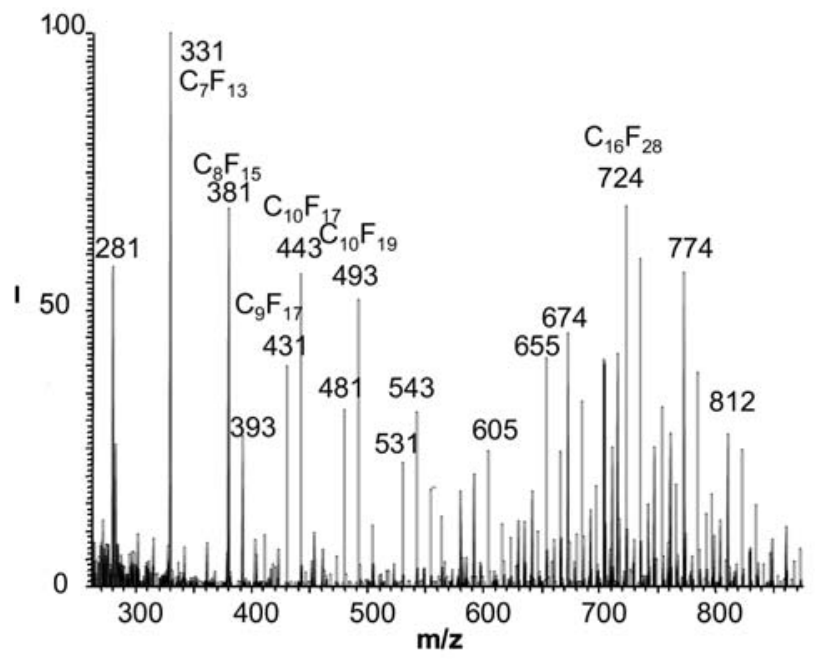

Figure 3. The negative ion APCI mass spectrum of perfluorokerosene obtained using the ASAP method showing ionization by EC and dissociative EC similar to Ni-DART [1].

straction reaction was studied by Horning et al. [5] and proposed to be the conversion of a Bronsted acid (BH) into its conjugate base $\left(\mathrm{B}^{-}\right)$by a proton abstraction reaction. By addition of chloroform into the gas plasma, they observed abstraction of a proton from certain compounds by proton abstraction with $\mathrm{Cl}^{-}$. The $\mathrm{Cl}^{-}$ion is formed by dissociative electron capture of chloroform. In a subsequent paper, Dzidic et al. [20] proposed that $\mathrm{O}_{2}{ }^{-}$. was a stronger base than $\mathrm{Cl}^{-}$and, thus, able to abstract protons from a wider array of compounds.

Thus, all four mechanisms of ionization observed in Ni-APPI and Ni-DART are also observed in Ni-APCI. Each of the compounds studied produced Ni-APCI mass spectra almost identical to those published using DART, but frequently with much improved sensitivity, probably due to the higher nitrogen gas vaporization temperature and/or the enclosed source purged with dry nitrogen used with ASAP. This suggests that, just as in the positive ion mode, ion/electron molecule reactions dictate the ionization mechanism rather than the initial method of producing the primary ions. For example, Horning et al. [5] initially use ${ }^{63} \mathrm{Ni}$ as a $\beta$-emitter for API, but later achieved the same results using discharge ionization [23].

\section{Conclusion}

The results presented here, as well as in previous published reports, demonstrate that EC, dissociative EC, proton abstraction, and chloride attachment negative ionization mechanisms are active in Ni-APCI. The similarities in analyte ionization between negative ion APPI, DART, and ASAP/APCI are a result of common ion/electron-molecule processes that occur at atmospheric pressure irrespective of the initial ionization process. The commonality of the ASAP and DART techniques is in agreement with recent publications that 
organize the growing number of direct API technique categories so that not only ASAP and DART, but also desorption atmospheric pressure chemical ionization [24], flowing afterglow-atmospheric pressure glow discharge [25], desorption atmospheric pressure photoionization [26], as well as other ambient ionization techniques fall in the category of thermal desorption (vaporization) with APCI ionization [27, 28]. Differences in sensitivity observed for the various techniques are more likely to be attributable to factors that affect ionization and vaporization as well as ion source and instrument parameters rather than the primary means of ionization.

\section{References}

1. Song, L.; Dykstra, A. B.; Yao, H.; Bartmess, J. E. Ionization Mechanism of Negative Ion-Direct Analysis in Real Time: A Comparative Study with Negative Ion-Atmospheric Pressure Photoionization. J. Am. Soc. Mass Spectrom. 2009, 20, 42-50.

2. Song, L.; Wellman, A. D.; Huifang, Y.; Bartmess, J. E. Negative IonAtmospheric Pressure. Photoionization: Electron Capture, Dissociative Electron Capture, Proton Transfer, and Anion Attachment. J. Am. Soc. Mass Spectrom. 2007, 18, 1789-1798.

3. Cody, R. B. Observation of Molecular Ions and Analysis of Nonpolar Compounds with the Direct Analysis in Real Time Ion Source. Anal. Chem. 2009, 81, 1101-1107.

4. Robb, D. B.; Covey, T. R.; Bruins, A. P. Atmospheric Pressure Photoionization Method for Liquid Chromatography Mass Spectrometry. Anal. Chem. 2000, 72, 3653.

5. Horning, E. C.; Horning, M. G.; Carroll, D. I.; Dzidic, I.; Stillwell, R. N. New Picogram Detection System Based on a Mass Spectrometer with an External Ionization Source at Atmospheric Pressure. Anal. Chem. 1973, 45, 936-943.

6. Horning, E. C.; Carroll, D. I.; Dzidic, I.; Haegele, K. D.; Lin, S.-N. Development and Use of Analytical Systems Based on Mass Spectrometry. Clin. Chem. 1977, 23, 13-21.

7. Horning, E. C.; Carroll, D. I.; Dzidic, I.; Haegele, K. D.; Horning, M. G. Atmospheric Pressure Ionization Mass Spectrometry, Solvent-Mediated Ionization of Samples Introduced in Solution and in a Liquid Chromatograph Effluent System. J. Chromatogr. Sci. 1974, 12, 725-729.

8. Caroll, D. I.; Dzidic, I.; Stillwell, R. N.; Horning, M. G.; Horning, E. C. Subpicogram Detection System for Gas-Phase Analysis Based Upon Atmospheric Pressure (API) Mass Spectrometry. Anal. Chem. 1974, 46, $706-710$.

9. Kauppila, J.; Bruins, A. P.; Kostiainen, R. Effect of the Solvent Flow Rate on the Ionization Efficiency in Atmospheric Pressure PhotoionizationMass Spectrometry. J. Am. Soc. Mass Spectrom. 2005, 16, 1399-1407.

10. Tsuchiya, M. Liquid Ionization Mass Spectrometry for Studies of Hydrogen-Bonded Clusters and of a Mixture That Contains Nonvolatile and Less Polar Organic Compounds. Mass Spectrom. Rev. 1998, 17, 51-69.

11. McEwen, C. N.; McKay, R. G.; Larsen, B. S. Analysis of Solids, Liquids, and Biological Tissues Using Solids Probe Introduction at Atmospheric
Pressure on Commercial LC/MS Instruments. Anal. Chem. 2005, 77, 7826-7831.

12. Kinouchi, T.; Miranda, A. T. L.; Rushing, L. G.; Beland, F. A.; Korfmacher, W. A. Detection of 2-Aminofluorene at Femtogram Levels via High-resolution Gas Chromatography Combined with Negative Ion Atmospheric Pressure Ionization Mass Spectrometry. J. High Resolution Chromatogr., Chromatogr. Commun. 1990, 13, 281-284.

13. Mitchum, R. K.; Korfmacher, W. A.; Moler, G. F.; Stalling, D. L. Capillary Gas Chromatography/Atmospheric Pressure Negative Chemical Ionization Mass Spectrometry of the 22 Isomeric Tetrachlorobenzo-p-Dioxins. Anal. Chem. 1982, 54, 719-722.

14. Mitchum, R. K.; Moler, G. F.; Korfmacher, W. A. Combined Capillary Gas Chromatography/Atmospheric Pressure Negative Chemical Ionization/ Mass Spectrometry for the Determination of 2,3,7,8-Tetrachlorodibenzo-pDioxin in Tissue. Anal. Chem. 1980, 52, 2278-2282.

15. Korfmacher, W. A.; Rowland, K. R.; Mitchum, R. K.; Daly, J. J.; McDaniel, R. C. Analysis of Snake Tissue and Snake Eggs for 2,3,7,8Tetrachlorodibenzo-p-Dioxan via Fused Silica GC Combined with Atmospheric Pressure Ionization MS. Chemosphere 1984, 13, 1229-1233.

16. McEwen, C. N.; McKay, R. G. A Combination Atmospheric Pressure LC/MS:GC/MS Ion Source: Advantages of Dual AP LC/MS:GC/MS Instrumentation. J. Am. Soc. Mass Spectrom. 2005, 16, (11), 1730-1738.

17. McEwen, C. N. GC/MS on an LC/MS Instrument Using Atmospheric Pressure Photoionization. Int. J. Mass Spectrom. 2007, 259, 57-64.

18. Engelbach, R. J.; Korfmacher, W. A.; Rushing, L. G. Analysis of Nitropyrenamines and Methylated Nitropyrenamines via Gas Chromatography-Negative Ion Atmospheric Pressure Mass Spectrometry. J. High Resolution Chromatogr., Chromatogr. Commun. 1988, 11, 661-663.

19. McEwen, C.; Gutteridge, S. Analysis of the Inhibition of the Ergosteral Pathway in Fungi Using the Atmospheric Solids Analysis Probe (ASAP) Method. J. Am. Soc. Mass Spectrom. 2007, 17, 1274-1278.

20. Dzidic, I.; Carroll, D. I.; Stillwell, R. N.; Horning, E. C. Atmospheric Pressure Ionization (API) Mass Spectrometry: Formation of Phenoxide Ions from Chlorinated Aromatic Compounds. Anal. Chem. 1975, 47, 1308-1312.

21. Singh, G.; Gutierrez, A.; Xu, K.; Blair, I. A. Liquid Chromatography/ Electron Capture Atmospheric Pressure Chemical Ionization/Mass Spectrometry: Analysis of Pentafluorobenzyl Derivatives of Biomolecules and Drugs in the Attomole Range. Anal. Chem. 2000, 72, 30073013.

22. Shen, Y.; Han, C.; Chen, J.; Wang, X. Analysis of Cyclic Peptides in Pseudostellaria heterophylla (Miq.) Pax by HPLC-APCI-MS. Chromatographia 2007, 66, 319-323.

23. Caroll, D. I.; Dzidic, I.; Haegele, K. D.; Stillwell, R. N.; Horning, E. C. Atmospheric Pressure Ionization Mass Spectrometry Corona-Discharge Ion Source for Use in Liquid Chromatography-Mass Spectrometry Computer Analytical System. Anal. Chem. 1975, 47, 2369-2373.

24. Cotte-Rodriguez, I.; Takats, Z.; Talaty, N.; Chen, H.; Cooks, R. G. Desorption Electrospray Ionization on Surfaces: Sensitivity and Selectivity Enhancement by Reactive Desorption Electrospray Ionization. Anal. Chem. 2005, 77, 6755-6764.

25. Andrade, F. J.; Shelley, J. T.; Wetzel, W. C.; Webb, M. R.; Gamez, G.; Ray, S. J.; Hieftje, G. M. Atmospheric Pressure Chemical Ionization Source. 1. Ionization of Compounds in the Gas Phase. Anal. Chem. 2008, 80, 2646-2653.

26. Haapala, M.; Pol, J.; Kauppial, T. J.; Kostiainen, R. Desorption Atmospheric Pressure Photoionization. Anal. Chem. 2007, 79, 7867-7872.

27. Venter, A.; Nefliu, M.; Cooks, R. G. Ambient Desorption Ionization Mass Spectrometry. Trends Anal. Chem. 2008, 27, 284-290.

28. Van Berkel, G. J.; Pasilisi, S. P.; Ovchinnikovia, O. Establishment and Emerging Atmospheric Pressure Surface Sampling/Ionization Techniques for Mass Spectrometry. J. Mass Spectrom. 2008, 43, 1161-1180. 